\title{
Corrosion behavior of AZ91 magnesium alloy treated by plasma immersion ion implantation and deposition in artificial physiological fluids
}

\author{
Chenglong Liu ${ }^{\mathrm{a}}$, Yunchang Xin ${ }^{\mathrm{a}, \mathrm{b}}$, Xiubo Tian ${ }^{\mathrm{a}, \mathrm{c}}$, Paul K. Chu ${ }^{\mathrm{a}, *}$ \\ a Department of Physics and Materials Science, City University of Hong Kong, Tat Chee Avenue, Kowloon, Hong Kong, China \\ b Tsinghua University, Shenzhen Graduate School, Shenzhen 518055, China \\ c State Key Laboratory of Welding Production Technology, School of Materials Science and Engineering, Harbin Institute of Technology, 15001, China
}

Available online 2 June 2007

\begin{abstract}
Due to the good biocompatibility and tensile yield strength, magnesium alloys are promising in degradable prosthetic implants. The objective of this study is to investigate the corrosion behavior of surgical AZ91 magnesium alloy treated by aluminum, zirconium, and titanium plasma immersion ion implantation and deposition (PIII\&D) at $10 \mathrm{kV}$ in artificial physiological fluids. The surface layers show a characteristic intermixed layer and the outer surface are mainly composed of aluminum, zirconium or titanium oxide with a lesser amount of magnesium oxide. Comparing the three sets of samples, aluminum PIII\&D significantly shifts the open circuit potential (OCP) to a more positive potential and improves the corrosion resistance at OCP.
\end{abstract}

(C) 2007 Elsevier B.V. All rights reserved.

PACS: 87.68.+z Biomaterials; 52.77.Dq Plasma-based ion implantation and deposition; 81.65.Kn Corrosion protection Keywords: Magnesium alloy; Plasma immersion ion implantation and deposition; Corrosion; Physiological fluid

\section{Introduction}

Magnesium alloys were first introduced into orthopedic and trauma surgery in the first half of the last century [1]. Compared to current implant materials such as $\mathrm{Ti}$ and titanium alloy, stainless steel and CoCr alloy, AZ91 magnesium alloys provide a lower elastic modulus (45 GPa) and higher tensile yield strength (200 MPa) [2]. However, the poor corrosion in physiological fluids has hampered widespread use in prosthetic devices. Although the development of casting technique has improved the corrosion resistance of magnesium alloys, the associated process is quite complex and costly. Plasma immersion ion implantation and deposition (PIII\&D) is one of the effective ways to synthesize an intermixed structure in the near-surface of materials for improved surface properties [3-5]. Some studies on metal or non-metal ion implantation with magnesium or magnesium alloy have recently been performed. Ion implantation of metal ions such as $\mathrm{Cr}$ [5], $\mathrm{Al}$ [6], Ta [7] can form a new oxidized film on the

\footnotetext{
* Corresponding author. Tel.: +852 27887724; fax: +852 27889549 .

E-mail address: paul.chu@cityu.edu.hk (P.K. Chu).
}

surface as well as an intermixed layer composed of the metallic compound resulting in enhanced corrosion resistance in different media. The effects of $\mathrm{N}^{+}, \mathrm{H}^{+}$, and $\mathrm{H}_{2} \mathrm{O}$ implantation on the corrosion behavior of magnesium alloy have been studied. The more compactness surface oxide layer in conjunction with $\mathrm{N}^{+}$or $\mathrm{H}_{2} \mathrm{O}$ implantation gives rise to higher corrosion resistance $[8,9]$. At the same time, formation of $\mathrm{MgH}_{2}$ enhances the corrosion resistance of $\mathrm{H}$-implanted high purity magnesium or AZ91 magnesium alloys [10]. These studies were conducted for industrial applications and the biological effects have not been extensively investigates. There have been few reports on the corrosion behavior of AZ91 Mg alloy after surface modification by metal plasma immersion ion implantation and deposition (PIII\&D) in simulated body fluids. In this work, we investigate the effects of different PIII\&D on the corrosion behavior of AZ91 magnesium in simulated body fluids.

\section{Experimental details}

Commercially available extruded AZ91 alloys with dimensions of $10 \mathrm{~mm} \times 10 \mathrm{~mm} \times 2 \mathrm{~mm}$ were prepared. The specimens were ground with water-proof $\mathrm{SiC}$ paper No. 400, 1200 and 
2400 grits sequentially and then ultrasonically washed in ethanol for $10 \mathrm{~min}$. In the aluminum, zirconium and titanium PIII\&D experiments, a metal vapor vacuum arc source was used and a pulsed high voltage of $-10 \mathrm{kV}$ was applied to the specimens. During the high-voltage off-cycles, deposition of metal particles occurred and ion implantation was conducted during the on-cycles. Implantation and deposition thus proceeded alternately and the PIII\&D time was $4 \mathrm{~h}$.

The surface composition and depth profiles were obtained by X-ray photoelectron spectroscopy (XPS, PHI 5802) by means of argon sputtering using a monochromatic $\mathrm{Al} \mathrm{K}_{\alpha}$ radiation. High-resolution XPS spectra were taken at different sputtered depths to investigate the chemical states of the implanted species. The corrosion and electrochemical behavior of the asreceived and PIII\&D specimens were studied in Hank's simulated body fluid (SBF) at $37 \pm 1{ }^{\circ} \mathrm{C}$. The open circuit potential (OCP) tests were conducted on an EG\&G 263A potentiostat/galvanostat. Changes in the OCP were recorded as a function of time during an exposure time of about $4000 \mathrm{~s}$. The electrochemical impedance spectroscopy (EIS) measurements were carried out on the GAMRY PCI4/300 at a stable OCP. The perturbing signal had an AC amplitude of $10 \mathrm{mV}$ and frequency range from $100 \mathrm{kHz}$ to $10 \mathrm{mHz}$. The data were analyzed through the software Gamry Echem Analyst.

\section{Results and discussion}

AZ91 alloy is mainly composed of $\mathrm{Mg}, \mathrm{Al}$, and $\mathrm{Zn}$. XPS measurements were carried out to determine the elemental concentration in the modified layer as a function of depth. Fig. 1 depicts the XPS depth profiles acquired from the Ti-PIII\&D AZ91 alloys. Fig. 1(a) shows a roughly Gaussian Ti depth distribution in the Ti-PIII\&D sample. The peak concentration is approximately 52 at. $\%$ at a depth of $\sim 28 \mathrm{~nm}$. At depths exceeding $40 \mathrm{~nm}$, the $\mathrm{Mg}$ and $\mathrm{Al}$ concentrations increase gradually. Fig. 1(b) depicts the changes in the $\mathrm{Mg}$, $\mathrm{Ti}, \mathrm{Al}$, and $\mathrm{O}$ valence states with depths. At the near-surface region, the $\mathrm{Mg} 1 \mathrm{~s}$ peak at $1302.7 \mathrm{eV}$ corresponds to $\mathrm{Mg}(\mathrm{OH})_{2}$. At a depth of about $40 \mathrm{~nm}$, the peak at $1304.0 \mathrm{eV}$ indicates the existence of $\mathrm{MgAl}_{2} \mathrm{O}_{4}$ and at $56 \mathrm{~nm}$, the peaks at $1303.1 \mathrm{eV}$ and $1304.0 \mathrm{eV}$ correspond to metallic Mg. Based on the Ti $2 p$ patterns in Fig. 2(a), the surface is composed partially of titanium oxide as indicated by the two

(a)

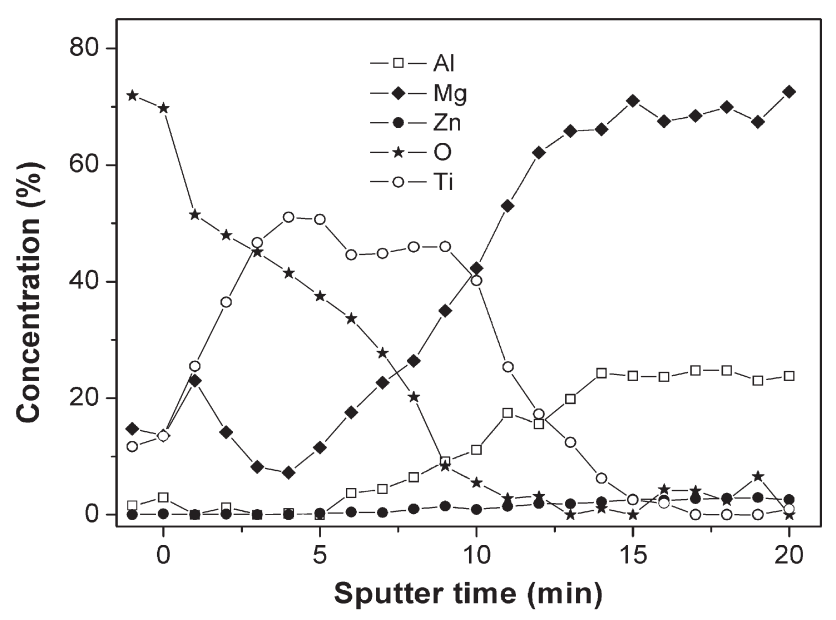

(b) $\quad$ Mg1s

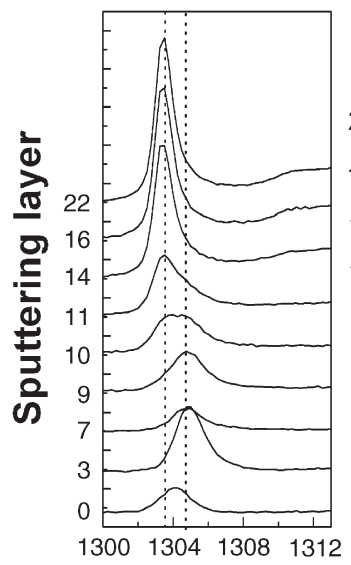

Al2p

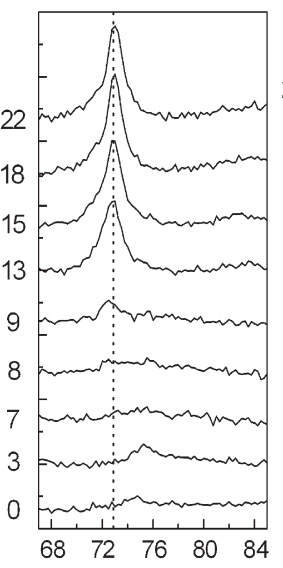

Ti2p

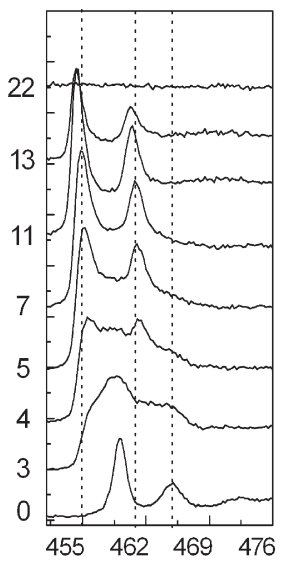

01s

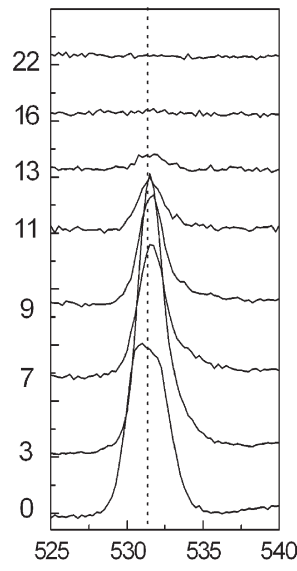

Binding energy (eV)

Fig. 1. (a) XPS depth profiles obtained from the magnesium alloy after Ti PIII\&D at $10 \mathrm{kV}$ (sputtering rate=5.6 nm/min). (b) High-resolution XPS spectra of Mg1s, A12p, Ti2p and O1s obtained from the Ti-PIII\&D magnesium alloy. 
peaks at $458.7(2 \mathrm{p} 3 / 2) \mathrm{eV}$ and $464.5(2 \mathrm{p} 1 / 2) \mathrm{eV}$. At depths exceeding $50 \mathrm{~nm}$, peaks at $454.2(2 \mathrm{p} 3 / 2)$ and $460.3(2 \mathrm{p} 1 / 2)$ arise from metallic $\mathrm{Ti}$ [11]. The alloy component $\mathrm{Al}$ is seen to exist mainly as oxide on the surface and as metallic $\mathrm{Al}$ in the subsurface as shown in Fig. 1(b). At depths up to $40 \mathrm{~nm}$, the Al $2 \mathrm{p}$ peak at $74.7 \mathrm{eV}$ corresponds to $\mathrm{Al}_{2} \mathrm{O}_{3}$ and between $40 \mathrm{~nm}$ and $60 \mathrm{~nm}$, the peaks at $74.3 \mathrm{eV}$ and $72.8 \mathrm{eV}$ coexist, implying the existence of $\mathrm{Al}_{2} \mathrm{O}_{3}$ and metallic Al. At depths over $60 \mathrm{~nm}$, the single peak at $72.9 \mathrm{eV}$ corresponds to metallic $\mathrm{Al}$ [11]. The relatively wide $\mathrm{O} 1 \mathrm{~s}$ peak shifts from $529 \mathrm{eV}$ to $534 \mathrm{eV}$ at the near-surface. It is almost asymmetric and can be deconvoluted into peaks corresponding to the $\mathrm{O}^{2-}$ state such as $\mathrm{Al}_{2} \mathrm{O}_{3}(531.1 \mathrm{eV}$, alpha $531.8 \mathrm{eV}$, gamma $530.9 \mathrm{eV}), \mathrm{MgO}$ $(530.0 \mathrm{eV}, 531.2 \mathrm{eV}, 532.1 \mathrm{eV})$ and $\mathrm{TiO}_{2}(529.9 \mathrm{eV})$ and one at $\sim 31.4 \mathrm{eV}$ corresponding to $\mathrm{OH}^{-}$species. At depths exceeding $60 \mathrm{~nm}$, the $\mathrm{O} 1 \mathrm{~s}$ peak becomes weaker [11]. The O 1s spectra confirm the compositional structure indicated by the other elements. Based on the XPS results, the tri-layer structure in the Ti-PIII\&D AZ91 alloy has the following compositions. The outer layer, about $10 \mathrm{~nm}$ thick, is mainly composed of $\mathrm{MgO}$ and $\mathrm{TiO}_{2}$ with less $\mathrm{Mg}(\mathrm{OH})_{2}$. The middle layer that is $50 \mathrm{~nm}$ thick comprises predominantly $\mathrm{TiO}_{2}$ and $\mathrm{MgO}$ with minor contributions from $\mathrm{MgAl}_{2} \mathrm{O}_{4}$ and $\mathrm{TiO}$. The third layer is rich in metallic $\mathrm{Mg}, \mathrm{Ti}, \mathrm{Al}$ and $\mathrm{Ti}_{3} \mathrm{Al}$. No abrupt boundaries among these layers are observed due to ion mixing.

The depth profiles of the Al-PIII\&D samples are shown in Fig. 2(a). At a depth of about $10 \mathrm{~nm}$, the $\mathrm{Mg}$ concentration is approximately 5 at. $\%$. An intermixed surface layer consisted of mainly aluminum oxide is formed. From $10 \mathrm{~nm}$ to $70 \mathrm{~nm}$, the aluminum concentration is relatively constant but the magnesium concentration increases quickly. At depths over $70 \mathrm{~nm}$, the Al concentration decreases gradually. The maximum Al concentration is about 35 at.\%. The results corroborate the formation of a triple-layer structure. Fig. 2(b) displays the highresolution XPS spectra of $\mathrm{Mg} \mathrm{1s}, \mathrm{Al} 2 \mathrm{p}$ and $\mathrm{O} 1 \mathrm{~s}$ taken at different depths. At about $10 \mathrm{~nm}, \mathrm{Al}_{2} \mathrm{O}_{3}$ and $\mathrm{Mg}(\mathrm{OH})_{2}$ are detected. With increasing depths, the amount of metallic aluminum increases as indicated by the increasing intensity of

(a)

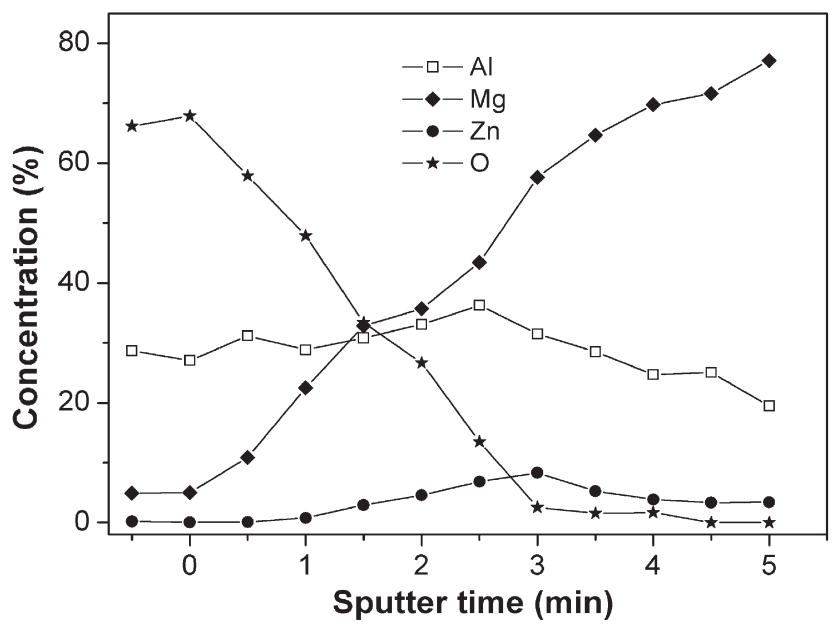

(b) Mg1s
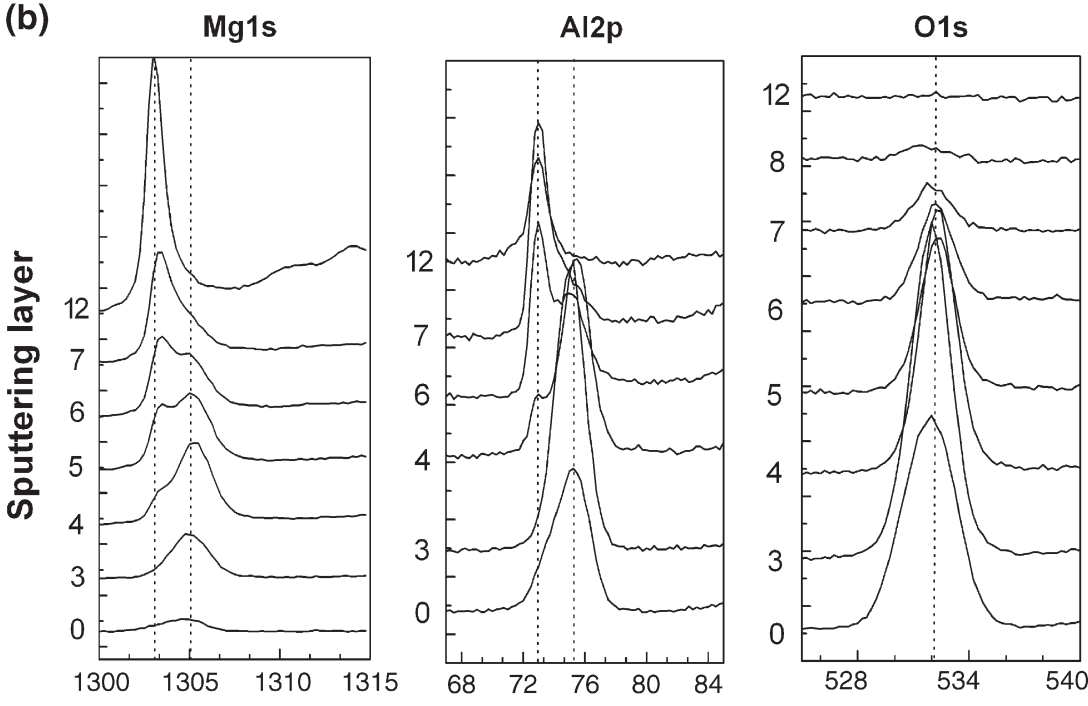

Bingding energy $(\mathrm{eV})$

Fig. 2. (a) XPS depth profiles obtained from the magnesium alloy after Al PIII\&D at $10 \mathrm{kV}$ (sputtering rate $=22.8 \mathrm{~nm} / \mathrm{min}$ ). (b) High-resolution XPS spectra of Mg1s, Al2p and O1s obtained from the Ti-PIII\&D magnesium alloy. 
an additional plasmon energy loss peak [12] at approximately $72.9 \mathrm{eV}$. The $\mathrm{Al}_{2} \mathrm{O}_{3}$ plasmon peak which is at $74.7 \mathrm{eV}$ diminishes in intensity with depths. At a sputter depth of approximately $80 \mathrm{~nm}$, only the peaks corresponding to metallic $\mathrm{Al}$ can be detected. In addition, the changes in the $\mathrm{Mg}$ valence states are similar to those of the $\mathrm{Ti}$ ion implanted samples. Considering the results in Fig. 2(a) and (b), the Al implanted layer is composed of the following microstructure: an outer layer (about $30 \mathrm{~nm}$ ) consisting of aluminum oxide rich layer with a lesser amount of $\mathrm{Mg}(\mathrm{OH})_{2}$, an intermediate layer rich in magnesium oxide with aluminum and zinc oxide as well as metallic elements, and a bottom layer composed of entirely metallic elements.

The zirconium depth distributions of the Zr-PIII\&D sample are shown in Fig. 3(a). The peak concentration of $\mathrm{Zr}$ is approximately 67 at.\% at a depth of $22 \mathrm{~nm}$. Compared to the $\mathrm{Al}$ and Ti-PIII\&D samples, the peak concentrations are different. The XPS spectra of the Zr-PIII\&D magnesium alloy are shown in Fig. 3(b) taken with increasing depths. The Mg 1s, Al 2p and O 1s XPS spectra are similar to those of the Ti-PIII\&D samples.
At depths between 0 and $20 \mathrm{~nm}$, zirconium exists in two forms: $\mathrm{ZrO}_{2}(182.4 \mathrm{eV})$ and $\mathrm{Zr}(178.9 \mathrm{eV})$ [11]. At larger depths up to $60 \mathrm{~nm}$, zirconia gradually changes to metallic zirconium. Here, the tri-layer zirconium implanted surface consists of an outer layer rich in zirconia, an intermediate layer composed of zirconium and magnesium oxide as well as metallic zirconium and magnesium, and a bottom layer consisting of the metallic elements.

The aforementioned results show the surface native oxide about $6 \mathrm{~nm}$ in thickness [13] is sputtered by during metal ion PIII\&D at $-10 \mathrm{kV}$. Under our non-UHV (ultra high vacuum) conditions (about $1.5 \times 10^{-5}$ Torr) in the PIII\&D chamber, surface oxidation is inevitable [15]. In addition, the elevated sample temperature during PIII\&D increases the thickness of this surface oxide. Our results indicate that the oxide formed in our process is more compact and may form a better protective layer.

With regard to the electrochemical results, compared to the as-received AZ91 alloy, the Al-PIII\&D specimens show the most positive OCP value after $4000 \mathrm{~s}$ immersion of about

(a)

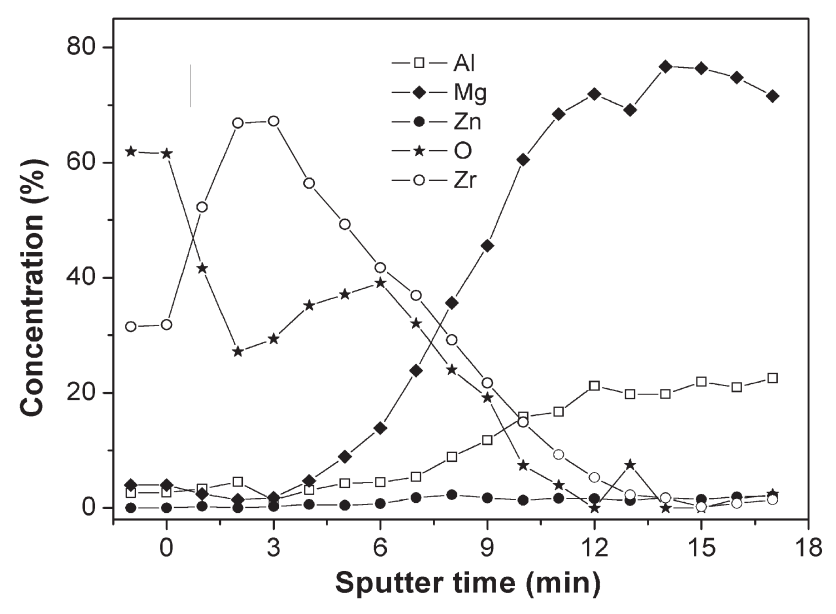

(b)

Mg1s

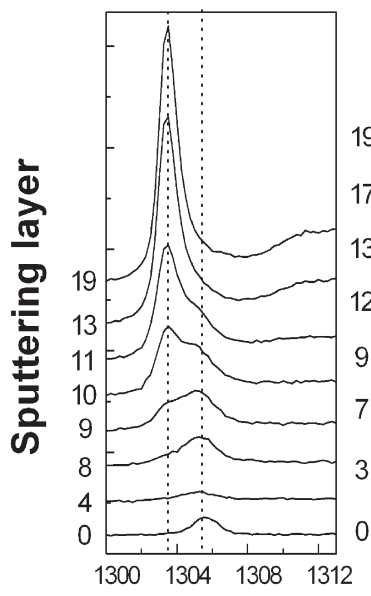

Al2p

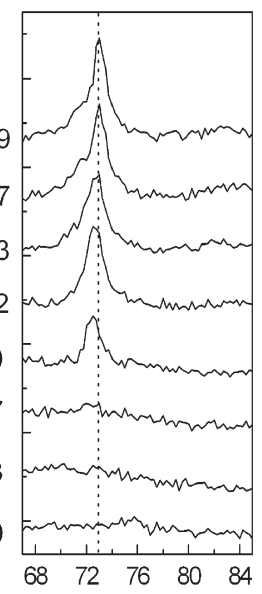

Zr3d

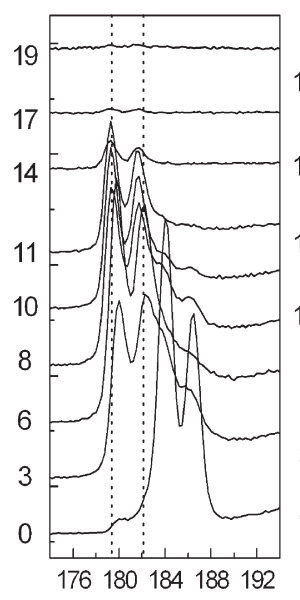

$01 \mathrm{~s}$

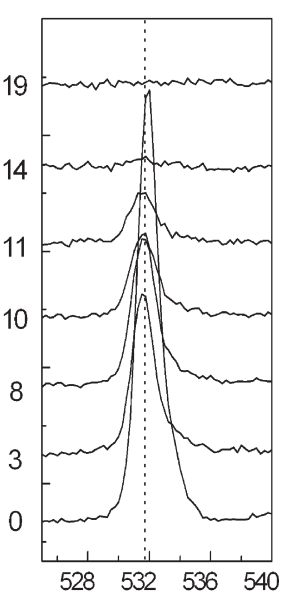

Binding energy /eV

Fig. 3. (a) XPS depth profiles obtained from the magnesium alloy after Zr PIII\&D at $10 \mathrm{kV}$ (sputtering rate $=5.6 \mathrm{~nm} / \mathrm{min}$ ). (b) High-resolution XPS spectra of Mg1s, $\mathrm{A} 12 \mathrm{p}, \mathrm{Zr} 3 \mathrm{~d}$ and $\mathrm{O} 1 \mathrm{~s}$ obtained from the $\mathrm{Zr}$-PIII\&D magnesium alloy. 
$0.036 \mathrm{~V}$, followed by $\mathrm{Zr}$ and Ti-PIII\&D specimens at $-0.545 \mathrm{~V}$ and $-0.696 \mathrm{~V}$, respectively. The increase in the OCP values indicates that the electrochemical stability of magnesium alloy can be improved by metal PIII\&D, especially aluminum.

Electrochemical impedance spectroscopy (EIS) is one of the most important techniques to investigate the electrochemical behavior of passivation films. Fig. 4 exhibits the Nyquist plots of the EIS spectra of the as-received and PIII\&D AZ91 alloys after $4000 \mathrm{~s}$ immersion in simulated body fluids. The spectra acquired from AZ91 are characterized by three distinct loops: capacitive in the high frequency range, capacitive in the intermediate frequency range, and inductive in the low frequency range. A closer look reveals differences in the spectra of the modified samples. The two capacitive loops at the high frequency range are fuzzy and an inductive loop in the low frequency range is clear. Here, it is suitable to use an equivalent circuit (EC) $\left(R_{e}\left(Q_{f} R_{f}\right)\left(Q_{d l} R_{t}\left(R_{l} L\right)\right)\right)$ to fit the parameters of the corresponding samples. The EC consists of $R_{e}$, resistance of the electrode between the working and reference electrodes, a charge transfer resistance, $R_{t}$ (electron transfer) parallel to the double layer constant phase element (CPE) at the vulnerable regions, $Q_{d l}$, and a $\mathrm{CPE}$ assigned to the layer, $Q_{f}$, parallel to the film resistance, $R_{f}$. The fitting error here is less than $10 \%$ (Table 1).

The observed difference in the Nyquist plots suggests different corrosion processes in the as-received and modified samples. $R_{f}$ is the relevant resistance for pore or ionic conducting defect resistance [15]. The EIS fits indicate that the Al-PIII\&D samples have $R_{f}$ values about one order of magnitude higher than the as-received samples of approximately $1210 \Omega \mathrm{cm}^{2}$, followed by zirconium PIII\&D. In contrast, titanium PIII\&D only has a small influence on the corrosion resistance which is about $441 \Omega \mathrm{cm}^{2}$ that is about 4 times higher than that of the as-received samples. The difference confirms that the corrosion protection provided by the native oxide film is inferior to that by the implanted and deposited metal particles. In the test solution, the protective oxide layer formed by metal ion PIII\&D helps to depress chemical dissolution, electrochem-

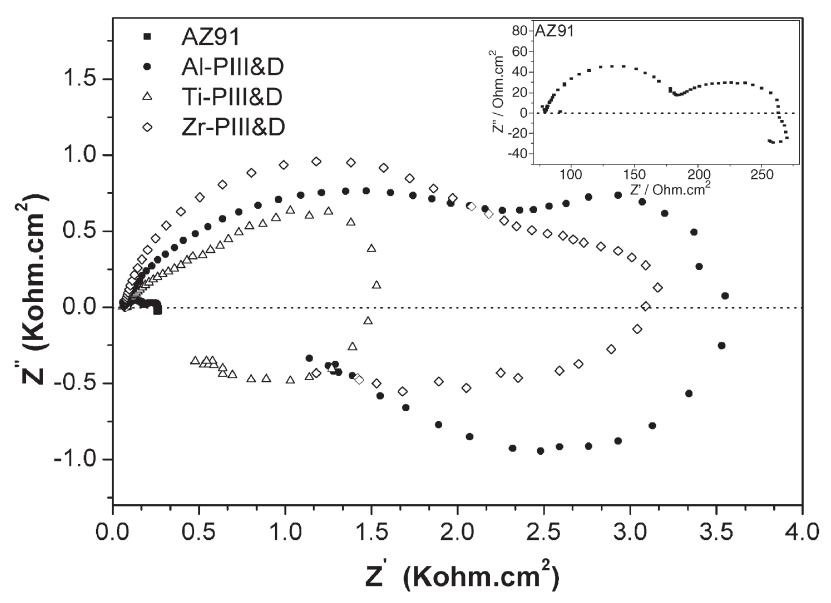

Fig. 4. Nyquist plots of the as-received and PIII\&D AZ91 alloy in simulated body fluids after $4000 \mathrm{~s}$ immersion.
Table 1

EIS fitting results obtained from the as-received and PIII\&D AZ91 alloy

\begin{tabular}{llcccc}
\hline Sample & $\begin{array}{l}R_{e} / \Omega \\
\mathrm{cm}^{2}\end{array}$ & $\begin{array}{l}Q_{f} / 10^{-5} \mathrm{~F} \\
\mathrm{~cm}^{-2}\end{array}$ & $\begin{array}{l}R_{f} / \Omega \\
\mathrm{cm}^{2}\end{array}$ & $\begin{array}{l}Q_{d l} / 10^{-5} \mathrm{~F} \\
\mathrm{~cm}^{-2}\end{array}$ & $\begin{array}{l}R_{t} / \Omega \\
\mathrm{cm}^{2}\end{array}$ \\
\hline AZ91 & 80.02 & 2.709 & 93.70 & 1.612 & 103.3 \\
A1-PIII\&D & 69.78 & 5.508 & 1210 & 48.15 & 2230 \\
Ti-PIII\&D & 69.73 & 6.852 & 442.10 & 12.82 & 1154 \\
Zr-PIII\&D & 69.20 & 23.71 & 755.50 & 60.25 & 2215 \\
\hline
\end{tabular}

ical reactions, and electrolyte penetration. The change in $R_{f}$ suggests different compactness of the implanted oxide layer. The XPS results show that Al or Zr PIII\&D creates an outer layer rich in $\mathrm{Al}_{2} \mathrm{O}_{3}$ or $\mathrm{Z}_{\mathrm{r}} \mathrm{O}_{2}$, which inhibits oxygen evolution from the implanted surface $[7,14]$. In contrast, the outer oxide layer on the Ti-PIII\&D samples is composed of $\mathrm{MgO}$ and $\mathrm{TiO}_{2}$ with less $\mathrm{Mg}(\mathrm{OH})_{2}$, and the existence of $\mathrm{MgO}$ may decrease the stability of the protective oxide layer [14]. The $R_{t}$ values reflect the Faradic charge transfer resistance related to electrochemical reactions in the vulnerable regions [15]. The asreceived samples have a low $R_{t}$ value of about $103 \Omega \mathrm{cm}^{2}$ which is approximately $1 / 20$ of that of the Al-PIII\&D samples. This can be ascribed to the difference in the corrosion products at the corrosion pits on the as-received and modified specimens. For the as-received specimens, the fast $\mathrm{H}_{2}$ evolution velocity mitigates precipitation of $\mathrm{M}(\mathrm{OH})_{\mathrm{n}}$ [15], and so the $R_{t}$ value is low. In contrast, it fosters precipitation of the corrosion products due to the lower corrosion rate of the PIII\&D specimens thereby enhancing the corrosion protection.

The micro-corrosion morphologies of the as-received and modified AZ91 alloy after EIS tests show severe corrosion attack on the AZ91 alloy. The corrosion holes which are not uniform arise from the $\alpha$ matrix and $\beta$ particles [15]. In comparison, less corrosion attack is found on the surface of the Al-PIII\&D samples. The corrosion morphologies are consistent with the EIS results. $R_{f}$ is a parameter reflecting the property of the passivation film. The Al-PIII\&D sample has the most positive $R_{f}$ value, and therefore, it suffers least corrosion attack. In comparison, the lowest $R_{f}$ value observed from the as-received sample corresponds to the most severe corrosion.

\section{Conclusion}

Titanium, aluminum and zirconium are plasma-implanted into AZ91 magnesium alloys to improve the corrosion resistance. Metal plasma immersion ion implantation and deposition results in an implanted layer with a tri-layer microstructure with an outer layer composed of mainly metal oxide with a small amount of $\mathrm{MgO}$ and $\mathrm{Mg}(\mathrm{OH})_{2}$, an intermediate layer containing metal oxide and metallic implanted particles, and a bottom layer rich in metallic elements. Electrochemical corrosion tests indicate that metal PIII\&D can improve the corrosion resistance of the magnesium alloy. Our results show the aluminum implantation and deposition offers the best corrosion protection and the enhancement can be attributed to the compact $\mathrm{Al}_{2} \mathrm{O}_{3}$ layer and thick intermixed layer. 


\section{Acknowledgements}

The work is financially supported by City University of Hong Kong Applied Research Grant (ARG) No. 9667011.

\section{References}

[1] F. Witte, V. Kaese, H. Haferkamp, H. Windhagen, Biomaterials 26 (2005) 3557.

[2] J.R. Davis, Handbook of Materials for Medical Devices, ASM International, USA, 2003.

[3] J.E. Gray, B. Luan, J. Alloys Compd. 336 (2002) 88.

[4] L. Kutsenko, D. Fuks, A. Kiv, I. Brown, Acta Mater. 16 (2004) 4329.

[5] J. Bruckner, R. Gunzel, E. Richter, W. Moller, Surf. Coat. Technol. 103-104 (1998) 227.
[6] M.K. Lei, P. Li, H.G. Yang, X.M. Zhu, Surf. Coat. Technol. 201 (2007) 5182.

[7] X.M. Wang, X.Q. Zeng, G.S. Wu, S.S. Yao, Mater. Lett. 61 (2007) 968.

[8] X.B. Tian, C.B. Wei, S.Q. Yang, R.K.Y. Fu, P.K. Chu, Surf. Coat. Technol. 198 (2005) 454.

[9] X.B. Tian, C.B. Wei, S.Q. Yang, R.K.Y. Fu, P.K. Chu, Nucl. Instrum. Methods Phys. Res., B Beam Interact. Mater.Atoms 242 (2006) 300.

[10] A. Bakkar, V. Neubert, Corros. Sci. 47 (2005) 1211.

[11] J.F. Moulder, W.F. Stickle, P.E. Sobol, Hankbook of X-ray Photoelectron Spectroscopy, Perkin-Elmer Corporation, USA, 1992.

[12] E. Wieser, I. Tsyganov, Surf. Coat. Technol. 111 (1999) 103.

[13] N. Hara, Y. Kobayashi, D. Kagaya, Corros. Sci. 5 (2006) 33.

[14] Y.Z. Liu, X.T. Zu, C. Li, Corros. Sci. 49 (2007) 1069.

[15] Y.J Zhang, C.W. Yan, F.H. Wang, W.F. Li, Corros. Sci. 47 (2005) 2816 